\title{
Australian Indigenous Knowledge in the Undergraduate Teaching Laboratory
}

\author{
Angela Ziebell ${ }^{\mathrm{a}, \mathrm{b}}$, Tina L. Overton ${ }^{\mathrm{a}, \mathrm{c}}$, Tyson Yunkaporta ${ }^{\mathrm{d}}$ \\ Corresponding author: Angela Ziebell (angela.ziebell@monash.edu) \\ ${ }^{a}$ School of Chemistry, Monash University, Melbourne, VIC, 3180, Australia \\ ${ }^{\mathrm{b}}$ School of Life and Environmental Sciences, Deakin University, Melbourne, VIC, 3125, Australia \\ ${ }^{c}$ Leeds Institute of Teaching Excellence, Leeds University, Leeds, LS2 9JT, England \\ ${ }^{\mathrm{d}}$ Institute of Koori Education, Deakin, Melbourne, VIC, 3125, Australia
}

Keywords: Indigenous perspectives, Indigenous knowledge (IK), IK/Medicine, Contextbased learning, graduate attributes

\begin{abstract}
The introduction of Indigenous knowledges (IK) and perspectives to the curriculum is an important step in decolonising the curriculum, and in reconciliation. This study explored the impact of a short laboratory project in the context of a traditional Aboriginal remedy (bush medicine), on final year Analytical Chemistry students.

Samples were taken from the Sandpaper fig both off- and on-country, and students designed their own investigation to determine whether the chemicals present differed with location. The activity required no dedicated cultural awareness training, and did not involve student interaction with an Indigenous academic. A video made by one of the authors supported the students' cultural learning and understanding.

The findings indicate that the students displayed a respectful consideration of IK and Indigenous perspectives. However, the students' inherent aversion to the idea of combining Indigenous and non-Indigenous knowledges, meant that they did not effectively bring Indigenous perspectives to bear within their own investigation. Students believed that the inclusion of Indigenous methods of inquiry in a modern laboratory setting made the IK feel inauthentic. We provide recommendations for more structured approaches to learning when integrating IK/perspectives and Western Scientific practices to allow students to comfortably navigate through IK within a modern context.
\end{abstract}

\section{Introduction}

The Transforming Laboratory Learning project (TLL) aimed to develop an engaging, modern curriculum based on sound pedagogy and incorporating context-based learning with opportunities for inquiry and varied assessment types (George-Williams et al., 2019; GeorgeWilliams, Ziebell, Thompson, \& Overton, 2020). Industrial context has recently been used in the design of a number of new laboratory programs (Bingham, Southee, \& Page, 2015; GeorgeWilliams et al., 2018; Pilcher, Riley, Mathabathe, \& Potgieter, 2015). These industrial contextbased activities aim to address a number of skills shortages seen in Science graduates e.g. commercial awareness, flexibility, ICT, and use of initiative (Sarkar, Overton, Thompson, \& Rayner, 2016; McGunagle \& Zizka, 2018) with an aim to enhancing graduate attributes (a set of high-level skills and understandings gained while studying at university). Another indemand skill for the modern workforce is intercultural competency (Brinkmann, 2014). Intercultural competence is commonly cited as a graduate outcome, but rarely defined, explicitly taught or assessed. Especially within New Zealand, Canada and Australia, there is a growing emphasis on cultural competency as a graduate attribute to enable graduates to work, with and for, Indigenous peoples, enhancing social justice and addressing inequities (Page, Trugett, \& Bodkin-Andrews, 2019). 
A pilot study was used to determine whether context-based learning could engage undergraduates in entry-level learning about the connection between Australian Indigenous culture and Science. The aim was to determine whether this small, accessible intervention could raise awareness and acknowledgement of IK/Medicine processes. This case study was designed to encourage the students to use the two sciences together, creating a new space which 'supports the creation of new understandings and knowledge' (Marika, 1999).

\section{Indigenous Knowledge/Science}

Indigenous knowledge (IK) is grounded in ecological relationships and a system of inquiry that has developed cumulatively over thousands of years (Diver, 2017). Within a rigorous discipline of IK that is holistic and interconnected (Popp, 2018), IK aligns with the complexity science principles of self-organisation, adaptability, non-linearity, and cross-scale interactions (Waltner-Toews \& Kay, 2005). As Colorado (1994) summarises, Indigenous science is just like western science in the sense that;

\section{"Indigenous science relies upon direct observation; there are tests to ensure validity and data are used for forecasting and generating predictions. Individuals are trained in various forecasting and generating predictions. Individuals are trained in various specialisations, for example, herbalism, weather observations, mental health and time}

$$
\text { keeping". }
$$

Indigenous medicinal knowledge is highly structured and grounded in specific social systems patterned on local ecosystems and cultural sites (Salmon et al., 2018). This structure means that it is not possible to explore IK separately from the key variable of place and the connected variable of time (Foley, 2003). Time and place are not separate concepts in Aboriginal worldviews, and in IK systems topographical sites of knowledge are the empirical mechanisms by which vast amounts of traditional knowledge can be stored across multiple generations (Fitzsimmons, 2016).

IK has provided important insights in environmental science (Nunn \& Reid, 2016) and other biology-related disciplines (Bennett et al., 2018), but it could be productively applied to many other areas of science through place-based activity and understanding (Barthel, 2017). The charters of international science organisations have recognised Indigenous knowledge as science and encourage dialogical approaches to inquiry incorporating aspects of both knowledge systems (Bala \& Joseph, 2007). Therefore, it is desirable to design tertiary science curricula that incorporate applications of Indigenous knowledge, rather than inclusion of token snippets of cultural information as additional content.

The context chosen explored the importance of belonging to place by looking at Ficus coronata (Sandpaper Fig) grown off-country (outside its natural biogeographic range), a garden on the university campus grounds, and on-country, the sample site was western Cape York, Queensland, Australia. The sandpaper fig is used by Indigenous communities to heal skin infections which are common during the wet season (Larcombe \& van Letten, 2018). The abrasive back of the leaf is used to abrade the skin and the sap from the leaf stem is massaged into the area. In a preliminary investigation Smyth, Ramachandran, Brooks and Smyth (2012), found ethanol extract of the sandpaper fig sap demonstrated antibacterial properties against multi-drug resistant Staphylococcus aureus. No literature could be found on the antifungal activity of the sandpaper fig. However, other Ficus species have demonstrated antibacterial and antifungal properties (Kumar et al., 2018). 
A context-based learning approach was used to embed IK into a chemistry laboratory project. As mentioned, context-based learning tends to increase student engagement. It is also an excellent way to introduce concepts external to the learning environment such as IK. The laboratory-based project was managed day-to-day by a teaching associate with no specific cultural competency training, and no prior experience with IK to ensure that the average tertiary teaching laboratory could replicate the conditions.

The Indigenous content developed included a video on Indigenous medicine. The video was filmed in a garden at the university campus constructed of plants traditionally used by Indigenous peoples around Australia. Students were later sent to harvest the off-country samples in this garden. The video tour was designed for students to gain a sense of how Australia's Indigenous Communities see the landscape as intimately interconnected.

During the video, time was introduced as a variable, first by noting that the Wurun tree was seeding, and that the seeding coincided with other seasonal phenomena in multiple species in the garden. Time was explained as an important variable, in the use of the sandpaper fig, as the lore (as taught to one of the authors by knowledge holders in western Cape York) indicates it will work in the wet season when the sap runs easily and skin infections are common. Attention was drawn to a number of other species to illustrate the importance of time and the interconnected nature of IK.

The video emphasised that cultural knowledge is not a series of facts but is constantly changing with time and place contexts. Within IK knowledge systems medicine is seasonal and can only be obtained under certain circumstances (i.e. right time and place). In an Indigenous method of inquiry there are no isolated variables as with western medicine. There are only interrelated variables situated in time and place. Like people, plants in the wrong place become systemically compromised and vulnerable to disease. The Sandpaper fig from Queensland and New South Wales was in the wrong place on the campus, and as a result it was dry, stunted and struggling. This sick tree is not producing sap when leaves are picked as it would further north.

In western medicine the variables of time and place are important but less central to investigations. Complexity theory in science is beginning to make room for the essential variables of time and place in research (Waltner-Toews \& Kay, 2005), so there are opportunities to be found in applying these aspects of Indigenous inquiry to scientific research. The use of the Sandpaper fig delivered the geographic variable to the students. Samples were accessed on-country by one of the researchers (see permissions to use below). With the variables of time and space, the study could attempt to examine the students' connection to place, often identified as a key cultural difference between Indigenous and non-Indigenous cultures.

\section{Materials and methods}

\section{Learning activity format}

Groups of four students were engaged in a six-week project (four hours per week in the laboratory) to harvest the off-country sample and analyse both on- and off-country samples by high performance liquid chromatography mass spectroscopy. On-country samples were collected for the students earlier in the year. Students were given three references discussing the testing of Ficus species for antimicrobial properties (Clarke, 2008; Maver et al., 2015; 
Packer et al., 2015) and one which analysed the exact plant samples within it's Indigenous range (Smyth et al., 2012), using a similar system to that available to the students.

The analytical method for the quantitative determination of phytochemicals in ethanolic extracts (Smyth et al., 2012) was provided to the students. Where students still had questions on how to proceed with their sample extraction, they had to determine the way forward themselves with general technical advice from the teaching assistant.

\section{Recruitment of students}

The project was offered as one of many projects to all students in the third-year Advanced Analytical Chemistry unit. No specialised recruitment of students into the project was performed. The description of the project appeared alongside other projects with a link to the four relevant papers described above. One of the authors visited the class before the projects started to ask if anyone had selected the project or had any questions about it. At this time, it was made clear that it was a new activity where students would have the opportunity to be part of the study presented here. Care was taken to ensure that answers were kept to the usual length and depth to minimise unduly influencing the students on their choice of project. A group of four students was formed in each of two different laboratory sessions (i.e. eight students total). One student withdrew from the unit. As there were only seven students in the study, we put this work forward as a case study with the plan to extend the study in future.

The context given for the inquiry was that a woman growing western herbal medicines wanted to try to grow a bush medicine or Aboriginal plant medicine. However, the farm was outside the area to which the sandpaper fig is indigenous. The farmer wanted an indication of whether the tree would produce similar chemicals if grown outside its native area as an indication of whether the sap is likely to be as medicinally relevant.

Before, during and after the project students were given a questionnaire of Likert questions and short open-ended questions to prompt their thinking on the topics of Perceptions of IK and Connection to Place. These questions took approximately 15 minutes to work through and were optional but all students completed them before, during and after the project. Students were asked, for example, how familiar, relevant, worthwhile or safe they thought Australian IK was (Likert). They were also asked 'what is your understanding of Aboriginal science and scientific knowledge and how did you come to that understanding?' Connection to country was explored with questions such as 'what health and identity impacts might be experienced by communities recently displaced from their place of origin?' and 'to what extent does your locality affect your culture/identity?' (short answer). The intention was to gain further insights into student's thinking however, the low number of students in the final study meant that this quantitative data was not further pursued as any changes would have been statistically insignificant.

\section{Focus groups}

An exploratory research methodology using semi-structured focus groups was used. Both authors hold to the Braun and Clarke interpretation of thematic analysis as being theoretically unbounded (Braun \& Clarke, 2006). All students agreed to participate in the session which was held outside of class time after the completion of laboratory time with lunch provided. Students were interviewed in focus groups based on their project teams directly after completing the "post" questionnaire. Transcription was performed by REV.com and final revisions performed by the authors. 
Students were first asked two general questions to elucidate how they experienced the laboratory project 1) 'How did you find this experience? Positive or negative?' and 2) 'What do you think you learnt/gained from working with a bush medicine context?'. How students understood connection to place was probed with the questions 3) 'What is your understanding of the idea of connection to place? Across all cultures?', 4) 'What do you think you learnt about belonging to place? For people and plants?' and 5) 'What were you thinking about when you were answering questions around connection to place?'. The context for the practical project was 'how much did place matter?' thus, the focus group questions were designed around eliciting responses based on what the students had learnt about connection to place.

Self-awareness of IK was investigated by asking the students 6) 'Do you feel your perceptions of $I K$ and medicine have changed? Why/why not?', 7) 'What did the practical context encourage you to think about if anything re perceptions of Indigenous sci/med?', 8) 'Are you interested in learning more about this area and has that changed due to the class? Why/why not?'. This was followed by the question 9) 'What were they thinking about when you answered: Australian IK is... Useful/useless, complicate/uncomplicated, exciting/boring etc.' followed by 10) 'what were you thinking of when you answered the statement questions?'. From the questionnaire it was known that the students had not studied the idea of IK previously. The focus group self-perceptions of IK questions were designed to probe how the students felt about IK after getting to the third year of university without encountering the concept. In total 65 minutes of audio recordings were collected.

\section{Data Analysis}

The focus group transcripts were analysed through inductive coding techniques. These themes were then assigned codes (using NVivo12) and one other education researcher and two research students independently assigned the codes to both transcripts. One coder was a migrant, one was second generation Australian, one was a seventh generation Australian, and one identified as Aboriginal. Two coders identified as female and two as male. This group of coders was assembled to insure against culturally influenced coding. The process of interrater reliability (Gwet, 2014; Braun \& Clarke, 2006) was continued until agreement was $>90 \%$.

\section{Permission to use samples}

Samples were accessed on-country by one of the researchers who is from that community and as such gained permission from the local Elders to collect samples. No further analysis was performed on the sample by the staff. Permission was not discussed in detail with the students however the students knew permission had been gained. The associated issues around intellectual property and plant use were not a part of this lesson.

\section{Results}

As the questionnaires were only used as primers and reflection for the students, the results that follow are an analysis of the interviews from the two focus groups.

\section{Perceptions of IK}

Seven themes were coded at a frequency greater than $5 \%$ of total responses of the focus groups in the Perceptions of IK section of the interview. Focus group A ( $N=4,32$ assignments), had more references to IK compared to focus group B ( $N=3,12$ assignments). The themes are summarised in Table 1 . When expressed as a percentage of all assigned themes, the most dominant theme overall was the Indigenous Knowledge theme (IK) with approximately one third of coded comments. 
Table 1: Thematic analysis of the Perception of IK responses in focus groups

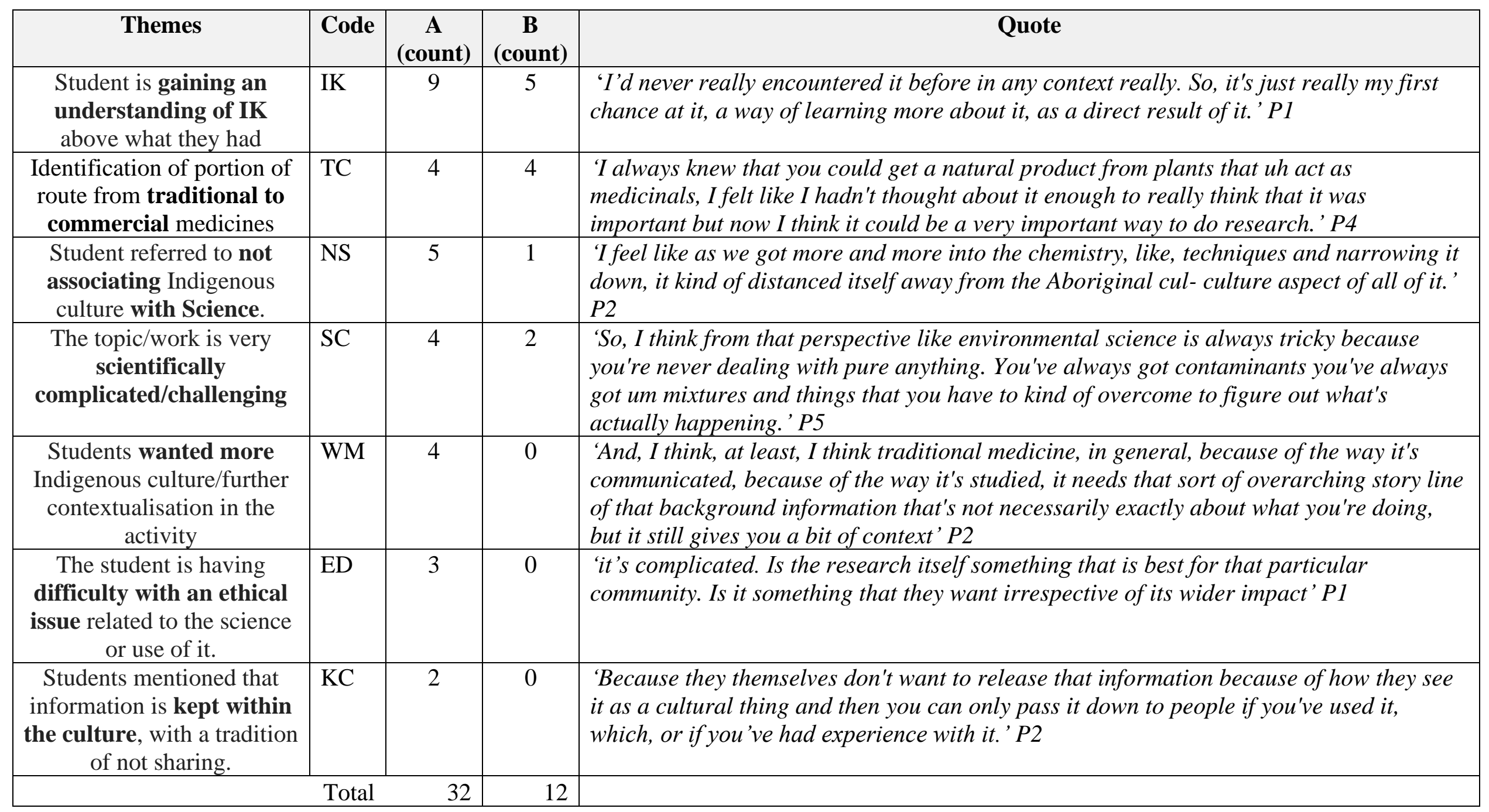


When talking about Perceptions of $I K$ in the focus groups some students communicated that the topic was so new to them that they had no perception of the topic before this class activity. For example, during the focus group the following was captured between two students in response to the question 'Do you feel your Perceptions of IK and medicine have changed? Why? Why not?'

'not having a perception as a baseline, you know. I had a reasonable understanding of Indigenous culture in general but not at the level of science, and medicine, and things like that, it had just never crossed my mind. 'P1

'Same here. For me, it was introduction to Indigenous traditional medicine.' P2

The students appear not to have come across the of concept of IK, only that there is Indigenous culture in Australia. In the second focus group a similar sentiment was raised in response to the same question. This time the student highlighted that they felt like they had been exposed to a large number of learning experiences around Indigenous culture in their schooling;

'I think they [perceptions] have changed, I was pretty familiar with the idea of...bush medicine. I mean it is probably gonna sound kind of silly but um most of my education around Indigenous Australian communities and culture came from primary school um and lots of kind of um incursions and excursions. And um considerable period of time spent about learning about their culture and the thing that they used. ...so I always had that kind of knowledge but I don't think I really ever considered it in a scientific context. I kind of just thought about it as more of a cultural thing' P3.

It appears that even when this student was exposed to cultural experiences over an extended period of time, they learnt about what they see solely as culture, and that the connection between the practices of Indigenous Australians and any science was not made. Participant 3 goes further saying;

'this project has kind of developed that into realising that, yes it may have been born from like a cultural kind of erm place but it it's grown for them to be like a science. And we should um appreciate it as more of a science than I think is currently widely regarded in the community and I think there's a lot sort of to be gained from it by regarding it as legitimate kind of science that has, I mean thousands of years of evidence on that now.' $\mathrm{P} 3$

It is clear from these quotes that, for these students, this small learning intervention has helped these students to accept IK as a concept. In the case of participant 3, the realisation has been significant enough for this student to propose that there is much to be gained from thinking about IK as a legitimate science with thousands of years of evidence. The failure to realise that an Indigenous culture would also incorporate Science may be a case of what Cobern colourfully called 'cognitive apartheid' in his work on Worldview theory (Cobern, 1996). Cobern describes students walling off knowledge for particular occasions. In this case it involves Indigenous Australia being associated with cultural elements like music, with students unable to realise that sophisticated storytelling and music would be associated with science. 


\section{Connection to Place}

Both focus groups were also asked about Connection to Place. Focus group A was comprised of three Australian born students and a student born in India and raised both in India and Australia. Focus group A did not yield any coherent material discussing Connection to Place while there was a significant discussion in focus group B. Instead, the transcript from focus group A shows significant discussion about their failure to generate results in their project. This contrasts between the result for the Perceptions of IK section, where focus group A had more assigned themes and a high rate of raising them (see table 2). No themes repeated between the two halves of the study.

The discussion from focus group B around Connection to Place also yielded fewer insights with the discussion being shorter, featuring less crosstalk and discussion, but with each student talking for longer when they did talk. Focus group B did generate results, however they were not of significant quality for them to be able to compare the two sites with any degree of certainty so there is little discussion of the actual results in the focus groups.

Focus group B included one student who had moved from China as a toddler and one student who had recently moved interstate to attend the university and experienced significant homesickness (P4). It is perhaps not surprising then that discussion in this focus group focussed more on place than focus group A.

Thematic analysis of the Connection to Place discussions yielded six themes (Table 2). The most frequently mentioned were identity/belonging and mental health, with the two often appearing in close proximity to each other as in this quote below:

'So, I think for me it's more of a mental health for me, you know I understand that that has implications for your mental health and then a knock on to physiological health. But I think for me yeah, it's more about um where I feel a strong sense of belonging and um what's the right word, I suppose I feel I feel most safe where I belong. And I think that that's my kind of interpretation of connection between health and place. It is less of a physiological thing for me and more of a mental health perspective.' P4

Participant 4 understood Connection to Place in terms of the impact on mental health (MH) a disconnection with place can have. This participant also articulated an association between connection to place and belonging (ID).

Physical health (PH), the connection to mental health (MH), and belonging (ID) were also discussed, for example by participant 5 below. However, throughout the focus group discussion on Connection to Place, the connection was phrased largely in terms of the students themselves and not in terms of the plant samples that they were examining. 
Table 2: Thematic analysis of the Connection to Place focus group responses

\begin{tabular}{|l|l|l|l|}
\hline Theme & Code & $\begin{array}{l}\text { B } \\
\text { (Count) }\end{array}$ & Quote \\
\hline $\begin{array}{l}\text { Student mentions that } \\
\text { identity or belonging is } \\
\text { involved }\end{array}$ & ID & 10 & $\begin{array}{l}\text { 'And even though I think I would be able to quite happily move away from it, it would } \\
\text { still no matter what remain a special place and a place that I associate very strongly } \\
\text { with.' P3 }\end{array}$ \\
\hline $\begin{array}{l}\text { Student discusses } \\
\text { implications of } \\
\text { connection to place on } \\
\text { mental health including } \\
\text { strong emotional states. }\end{array}$ & $\mathrm{MH}$ & 9 & $\begin{array}{l}\text { 'I've been in Melbourne like 20 times, like it is different moving and leaving where you } \\
\text { belong and like I got really bad like, I just like I don't know I cried everyday like I just, I } \\
\text { was like fine but like I wasn't fine.' P4 }\end{array}$ \\
\hline $\begin{array}{l}\text { Student mentions a } \\
\text { religious or cultural } \\
\text { connection to place }\end{array}$ & $\mathrm{RC}$ & 7 & $\begin{array}{l}\text { 'connection to place I think varies from like community to community um but when you } \\
\text { look at it like the perspective of an Indigen- Indigenous Australian at least for me, is } \\
\text { that I think that um for lots of western cultures there's religion.' P3 }\end{array}$ \\
\hline $\begin{array}{l}\text { Making or breaking } \\
\text { connection to place (+ } \\
\text { for making, - for } \\
\text { breaking) }\end{array}$ & $\mathrm{CP}$ & 7 & $\begin{array}{l}\text { On immigration as a toddler 'Yeah so like I moved when I was very little so I feel like I } \\
\text { had like a slightly easier kind of transition because I wasn't like as established.' P5 }\end{array}$ \\
\hline $\begin{array}{l}\text { A plants connection to } \\
\text { place }\end{array}$ & $\mathrm{PC}$ & 6 & $\begin{array}{l}\text { 'If there was no variation in the connection of the plant place then wouldn't the entire } \\
\text { world all have the exact same plants. It's like I mean-. (laughs)...but, in all seriousness } \\
\text { though.' P5 }\end{array}$ \\
\hline $\begin{array}{l}\text { Implications of } \\
\text { connection to place on } \\
\text { physical health }\end{array}$ & $\mathrm{PH}$ & 4 & $\begin{array}{l}\text { 'like I know if you leave everything that you know can make you feel depressed, which } \\
\text { can then to lead to like sleep deprivation which could lead to so many different like } \\
\text { issues with health' P4 }\end{array}$ \\
\hline
\end{tabular}




\section{Discussion}

This case study aimed to assess the impact of a 6-week bush medicine laboratory project on students Perception of IK and Connection to Place. When asked about the Perception of IK students reported gaining an understanding of IK above what they already had. Some students specifically reported that they had previously not associated Indigenous culture with science. There was also recognition that bush medicine is very scientifically complex. As chemistry students they could see the bush medicine context as highlighting the historically important route of finding commercially viable products from traditional medicine. However, this was clearly associated with references to the importance of avoiding exploitative practices and respecting Indigenous people's right to sovereignty over their knowledge as expressed by P1 below;

'I'm a fan if they want to keep their ideas and stuff like contained so that they have control over it, and it doesn't go too far or get exploited in some way, that they may not want, but at the same time, it's difficult, then, for, them (bush remedies) to be useful to more people apart from just being in that specific culture' $P 1$

Focus group discussion around Connection to Place resulted in students talking about identity/belonging, as well as mental/physical health. Students reported a belief that mental and physical health are closely interlinked. Religious and cultural connections were used in a largely interchangeable way, which was notable as none of the class activity questions or the focus group questions mentioned religion. While religion is a cultural construct the two are not synonymous, at least in the Australian context. The use of religion and culture interchangeably could indicate an attempt by the students to relate Connection to Place to, what is for them, the most similar process in mainstream Australia i.e., religion.

\section{Perception of IK}

The three strands of science that are currently being used for the inclusion of IK in Australian curricula are Science as Human Endeavour, Science as Inquiry and Science as Understanding (ACARA 2019). Our project falls under the strand of Science as Inquiry, which focuses on Indigenous knowledge informing methodologies, techniques and processes of investigation. This requires engagement not only with Indigenous scientific knowledge, but also extending this into being able to approach all scientific knowledge 'Indigenously' (Arabena, 2015), or teaching Indigenous perspectives.

With a history of over two centuries of work discrediting Indigenous ways of life in Australia, the responses given by the participants in this study demonstrate it is possible that one small project introducing the concept of IK can work meaningfully towards removing preconceived ideas around the lack of sophistication of Indigenous life. Importantly, it is a step toward correcting the deficit model which is dominant in today's narrative on many things Indigenous. However, the quote in Table 1 exemplifying the code NS, warns of a limit to what has been demonstratable in this work. The participant does not appear to feel as though the Indigeneity of the project ('Aboriginal culture') persisted once the students were asked to interrogate the samples with laboratory instrumentation.

This study has raised the important point that this connection between Indigenous ways of life and science is not frequently covered in early years, although significant work has recently been done to provide curriculum examples (ACARA, 2019). Therefore, school incursions in 
Australia present an opportunity to introduce this link between Indigenous culture/life and science much earlier. Introducing the idea of IK in primary school education would add significant depth and sophistication to the story Australian children generally hear about Australia's first peoples. IK in primary school could correct the deficit model at a larger scale than any interventions at the tertiary level could hope to achieve.

\section{Connection to place}

The laboratory work was designed around the variable of place, under the Indigenous heuristic of interspecies communication between plant and human (Tonkinson, 2011). IK arises from dynamic systems profoundly situated in unique localities and ecosystems (Durie, 2005). The aim was that the scientific method the students would use for their laboratory work would be enriched by the innovative combination of western and Indigenous bodies of scientific knowledge (Mafile'o, Mitera, \& Mila, 2019). It was planned that the different chemical profiles of these two plant entities would 'speak' to the students and empirically affirm for them the importance of the variable of place in processes of inquiry.

The connection to place aspect of the laboratory project appears to have been less successful. As noted above, none of the students discussed Connection to Place with respect to the samples that they collected and tested. Discussions around Connections to Place revolved around student identity and mental health. Students were able to include plants in these discussions, but it was passingly in terms of food and place, or food, comfort and familiarity. Explicit education around the Indigenous concept of Connection to Place is likely needed to further this learning goal. This is challenging within the confines of an individual subject, and therefore a goal for the degree or Faculty level. Access to central resources for teaching students has previously been uncommon for most universities, however, universities are rapidly rolling out institution-wide training for staff. In addition, there are examples of high-quality institutional training resources that will provide the background level of Indigenous cultural competency, which can then be built upon within curricula.

As mentioned above, the students appeared to have an inherent aversion to the idea of combining Indigenous and non-Indigenous knowledge. In hindsight, one problem was maintaining the assessment as a traditional chemistry report. Greater use of constructive alignment of the assessment could minimise this problem. For example, changing the student report of the results to be a report to the farmer and the Traditional Owners she was working with would help re-enforce that the students had community permission to test the antifungal properties. Such framing has to be carefully discussed with community groups. In this case the students did have permission from knowledge holders in western Cape York to look at the plant samples in the laboratory specifically in order to investigate possible antifungal compounds. This permission is crucial as concepts of knowledge sovereignty and Indigenous people's rights to self-determination of their knowledge must be modelled to students, lest we do more harm than good embedding Indigenous knowledges and perspectives.

More generally, constructive alignment which ensured that the student had to use both the Indigenous perspective and the Western perspective would maximise the chance for students to achieve the cultural learning outcomes (Wiggins, 1993). Explicitly directing students to do this is likely an important first step in helping the students work with this discomfort. As the students were highly receptive to the video, this might be a useful place to include such support and enhance opportunities for students to approach scientific knowledge 'Indigenously'. By 
which we mean applying elements of Indigenous processes and methods of inquiry, such as including time and place as variables in chemical analysis.

\section{Limitations}

It is recognised that this was a case study involving seven individuals comprising two project groups and two focus groups. As such the study findings cannot be generalised to tertiary Australian science students but instead can be used to gain an insight into the thoughts and reactions that students can have when a multiweek activity is given an IK context. This activity was an opt-in project as that is how projects are always run within this class and the unit coordinator wanted to continue with that approach. Therefore, students could have been more willing than average to accept the concept of IK.

It should be noted that participation in the questionnaire pre-, mid and post activity likely influenced the experience of the students. While it is impossible to assess the impact of having students think about the questions in the questionnaire several times, it is reasonable to propose that dedicating time to answering the questions and participating in the focus group could have raised students' awareness of the issues. The importance of reflection in learning (Boud, Keogh, \& Walker, 1985) should be kept in mind when adding Indigenous contexts to the curriculum. Completing the questionnaires and taking part in the focus groups likely encouraged such reflection from the participants. It is valuable not just to add Indigenous context and perspectives to the curriculum but to introduce opportunities to reflect on the experiences.

The activity was deliberately given no additional educational support to ensure that the findings of the study would be as widely translatable as possible to other teaching contexts. For example, an intervention of this type can be run without specialist Indigenous academic support for the teaching component, instead this study had video support. This is not to say that the specialist assistance is not needed to help design the activity or train the staff. However, we recognise that not everyone wanting to add an Indigenous context to their curriculum will have the ability to put Indigenous staff in the classroom. As work in embedding Indigenous contexts into the curriculum expands, we believe that the level of design assistance provided for this activity is a realistic level of support for many educators and faculties.

\section{Conclusions}

Our hypothesis was that Indigenous orientations of inquiry would produce replicable laboratory results affirming the validity of IK as a scientific paradigm. However, the actual laboratory results were not discussed by the students. Instead, there were unexpected findings that illuminate some barriers to IK inclusion that remain largely unexplored in the literature. These pertain to perceptions of transferability of IK across different domains of knowledge, perceptions which relegate IK to the domain of additional or token content rather than being included as a rigorous/useful system of inquiry in its own right.

Analysis of the qualitative data suggested that these findings were linked to two factors - the students' own disconnection between place and identity, but more importantly their inherent aversion to combining Indigenous and non-Indigenous knowledges. They expressed concern that the inclusion of Indigenous methods of inquiry in a modern laboratory setting made the IK feel less authentic. They were enthusiastic about touring the garden and watching the virtual tour on film as this felt authentic, and they expressed interest in including traditional knowledge 
as additional content in their curriculum. However, an important finding is that students were actively resistant to the notion of applying Indigenous knowledge in a laboratory setting.

It is possible that this outcome can be attributed to the inherent reductionism of the laboratory context, producing an aversion to including variables of time/season and place/country in experimental methodologies. Potentially this 'cognitive apartheid' arising from a mismatch in knowledge systems represents more of a barrier to embedded Indigenous perspectives than basic prejudice or lack of cultural awareness. Students who are enthusiastic about learning Indigenous content, and instructors who are keen to share it, may still find it difficult to reconcile Indigenous and non-Indigenous knowledge systems in productive ways. Attempts to add IK to the curriculum without accounting for this reluctance will likely be less successful. However, we propose that supportive introductory material, and constructive alignment bringing the IK overtly into the assessment, may act to ameliorate this phenomenon.

\section{Acknowledgements}

Thank you to Krystal De Napoli, Nathan Sos, and Elizabeth Leong for help in inter-rater reliability assessment.

\section{Ethics approval}

This project has the approval of the Monash University human ethics committee (No. 2016000584).

\section{References}

ACARA (2019). https://www.australiancurriculum.edu.au/f-10-curriculum/science/.

Arabena, K. (2015). Becoming Indigenous to the universe: reflections on living systems, Indigeneity and citizenship. Melbourne: Australian Scholarly Publishing.

Bala, A., \& Joseph, G. (2007). Indigenous knowledge and western science: the possibility of dialogue. Race and Class, 49(1), 39-61.

Barthel, R. S., R. (2017). Interdisciplinary collaboration between natural and social sciences - status and trends exemplified in groundwater research. 12(1), e0170754.

Bat, M., Kilgariff, C. \& Doe, T. (2014). Indigenous tertiary education - we are all learning: both-ways pedagogy in the Northern Territory of Australia. Higher Education Research \& Development, 33(5), 871-886.

Bennett, N., Whitty, T., Finkbeiner, E., Pittman, J., Bassett, H., Gelcich, S. \& Allison, E. (2018). Environmental stewardship: a conceptual review and analytical framework. Environmental Management, 61, 597-614.

Bingham, G. A., Southee, D. J., \& Page, T. (2015). Meeting the expectation of industry: an integrated approach for the teaching of mechanics and electronics to design students. European Journal of Engineering Education, 40(4), 410-431, doi:10.1080/03043797.2014.1001813.

Boud, D., Keogh, R., \& Walker, D. (1985). Reflection: turning experience into learning. London and New York: Routledge Falmer Taylor \& Francis Group.

Braun, V., \& Clarke, V. (2006). Using thematic analysis in psychology. Qualitative Research in Psychology, 3(2), 77-101, doi:10.1191/1478088706qp063oa.

Brinkmann, U. (2014). Intercultural readiness. UK: Palgrave Macmillan.

Clarke, P. (2008). Aboriginal healing practics and Australian bush medicine. Journal of the Anthropological Society of South Australia, 33, 3-38.

Cobern, W. W. (1996). Worldview theory and conceptual change in science education. Science Education, $80(5), 579-610$.

Colorado, A. (1994). Nine distinctions of Indigenous Science Worldwide INdigenous Science Network Retrieved October 15 ${ }^{\text {th }}, 2021$ https://library.wisn.org/2015/05/28/nine-distinctions-of-indigenous-science-2/

Diver, S. (2017). Negotiating Indigenous knowledge at the science policy interface: insights from Xaxli'p community forest. Environmental Science and Policy, 73(July), 1-11.

Durie, M. (2005). Indigenous Knowledge within a Global Knowledge System. Higher Education Policy, International Association of Universities; 18, 301-312. Fitzsimmons, H. (2016, October 12). The world's oldest observatory? How Aboriginal astronomy provides clues to ancient life. Retreived June 29, 2021, from https://www.abc.net.au/news/2016-10-12/aboriginal-astronomy-provides-clues-toancient-life/7925024

Foley, D. (2003). Indigenous epistemology and Indigenous standpoint theory. Social Alternatives, 22(1), 44-52. 
George-Williams, S. R., Soo, J. T., Ziebell, A. L., Thompson, C. D., and Overton, T. L. (2018) Inquiry and industry inspired laboratories; the impact of students' perceptions of skill development and engagements Chemistry Education Research and Practice, 19, 583-596.

George-Williams, S. R., Karis, D., Ziebell, A. L., Kitson, R. R. A., Coppo, P., Schmid, S., et al. (2019). Investigating student and staff perceptions of students' experiences in teaching laboratories through the lens of meaningful learning. Chemistry Education Research and Practice, 20(1), 187-196.

George-Williams, S. R., Ziebell, A. L., Thompson, C. D., \& Overton, T. L. (2020). Inquiry-, problem-, contextand industry- based laboratories: an investigation into the impact of large-scale, longitudinal redevelopment on student perceptions of teaching laboratories. International Journal of Science Education, 42(3), 451-468, doi:DOI: 10.1080/09500693.2020.1714788.

Gwet, K. L. (2014). Handbook of inter-rater reliability: The definitive guide to measuring the extent of agreement among raters. (3ed.). Gaithersburg, MD, USA: Advanced Analytics, LLC.

Jackson, D., \& Collings, D. (2018). The influence of work-integrated learning and paid work during studies on graduate employment and underemployment. Higher Education, 76, 403-425.

Kumar, S., Singh, A., Kushwaha, A. K., Tiwari, R., Chaudhary, L. B., Srivastava, M., et al. (2018). The UPLCESI-QqQLIT-MS/MS method for quantitative determination of phytochemicals in ethanolic extracts of different parts of eight Ficus species: Development and validation. International Journal of Food Properties, 21(1), 328-344, doi:10.1080/10942912.2017.1414838.

Larcombe, D.-L. \& van Letten, E. (2018, May 24). Sandpaper figs make food, fire, medicine and a cosy home for wasps. The Conversation. Reteived June 29, 2021, from https://theconversation.com/sandpaper-figsmake-food-fire-medicine-and-a-cosy-home-for-wasps-96404

Mafile'o, T., Mitera, J. \& Mila, K. (2019). Pacific-Indigenous social work theories. In J. Ravulo, T. Mafil'o, \& D. Bruce-Yates (Eds.), Pacific Social Work: Navigating practice, policy and research. New York.: Routledge.

Malterud, K., Siersma, V. D., \& Guassora, A. D. (2016). Sample size in qualitative interview studies: guided by information power. Qualitative Health Research 1, 26(13), 1753-1760.

Marika, R. (1999). Milthun latju wangu romgu Yolngu: valueing Yolngu knowledge systems in the education system. Ngoonjook, 16, 107-120.

Maver, T., Maver, U., Kleinschek, K. S., Smrke, D. M., \& Kreft, S. (2015). Review of herbal medicines in wound healing. International Journal of Dermatology, 54(7), 740-751, doi:10.1111/ijd.12766.

McGunagle, D., \& Zizka, L. (2018). Meeting real world demands of the global economy: an employer's perspective. Journal of Aviation/Aerospace Education \& Research, 27(2), 59-76, doi:10.15394/jaaer.2018.1738.

Nunn, P. D., \& Reid, N. J. (2016). Aboriginal memories of inundation of the Australian coast dating from more than 7000 years ago. Australian geographer, 47(1), 11-47, doi:10.1080/00049182.2015.1077539.

Packer, J., Tarannum, N., Yaegl Community Elders, Harrington, D., Jamie, J., \& Subramanyam, R. V. (2015). Antimicrobial activity of customary medicinal plants of the Yaegl Aboriginal community of nothern New South Wales, Australia: a preliminary study. BMC Research Notes, 8, $276-282$.

Page, S., Trugett, M., \& Bodkin-Andrews, G. (2019). Creating a degree-focused pedagogical framework to guide Indigenous graduate attributes curriculum development. Higher Education, 78, 1-15.

Pilcher, L., Riley, D., Mathabathe, K., \& Potgieter, M. (2015). An ilnquiry-based practical curriculum for organic chemistry as preparation for industry and postgraduate research. South African journal of chemistry. Suid-Afrikaanse tydskrif vir chemie, 68, 236-244, doi:10.17159/0379-4350/2015/v68a32.

Popp, J. (2018, Janurary 3) How Indigenous knowledge advances modern science and technology. The Conversation. Retrieved June 28, 2021, from https://theconversation.com/how-indigenous-knowledgeadvances-modern-science-and-technology-89351

Salmon, M., Doery, K., Dance, P., Chapman, J., Gilbert, R., Williams, R., et al. (2018). Links between Aboriginal and Torres Strait Islander culture and wellbeing: what the evidence says, Mayi Kuwayu: The National study of Aboriginal and Torres Strait Islander wellbeing. Canberra: ANU.

Sarkar, M., Overton, T. L., Thompson, C. D., \& Rayner, G. (2016). Graduate employability: Views of recent science graduates and employers. International Journal of Innovation in Science and Mathematics Education, 24(3), 31-48.

Smyth, T. J., Ramachandran, V., Brooks, P., \& Smyth, W. F. (2012). Investigation of antibacterial phytochemicals in the bark and leaves of Ficus coronata by high-performance liquid chromatographyelectrospray ionization-ion trap mass spectrometry. Electrophoresis, 33(4), 713-718, doi:10.1002/elps.201100302.

Tonkinson, R. (2011). Landscape, Transformations and Immutability in an Aboriginal Australian Culture. Perth: The University of Western Australia. 
International Journal of Innovation in Science and Mathematics Education, 29(2), 32-46, 2021

Waltner-Toews, D., \& Kay, J. (2005). The evolution of an ecosystem approach: the diamond schematic and adaptive methodology for ecosystems sustainability and health. Ecology and Society, 101.

Wiggins, G. P. (1993). Assessing student performance. San Francisco, USA: Jossey-Bass. 